\title{
An Evidence-Based Perspective of the Self-Management of Middle School Students
}

\author{
Weijie Meng, ${ }^{1}$ Fengqi Ning $^{2}$ \\ 1. Principal of Nanjing Yutong Experimental School, 22 Jiangjun Avenue, Jiangning District, Nanjing 211100, Jiangsu, China \\ 2. Nanjing Yutong Experimental School, 22 Jiangjun Avenue, Jiangning District, Nanjing 211100, Jiangsu, China \\ Correspondence to: Fengqi Ning, Email: 872225979@qq.com \\ DOI: https://doi.org/10.15354/si.21.re079 \\ The authors declare no competing interest
}

The ability of self-management is an essential ability for the sustainable development of humankind. Student self-management is a vital organic part of student self-development education. Under the practical guidance of school administrators, students play their initiative in life and study, conduct self-discipline and management, which is conducive to the life-long development of students, especially for middle school students who are in the critical stage of adolescence, the use of students' self-management to guide the development of ideas and the formation of personality. Starting from self-management, this article summarizes and integrates the definition and connotation of student self-management. On the basis of defining the related concepts of students' self-management, starting from the three aspects of theory, practice and evaluation, we will discuss the theoretical basis of students' self-management, the content of students' self-management, the problems existing in the students' self-management practice and the measures taken. To study the current situation of existing middle school students' self-management and its application to provide a reference for further optimizing the self-management strategy of middle school students, exerting the value of self-management of students, and cultivating the self-management ability of middle school students.

Keywords: Middle School Students; Self-Management; Review; Perspective

Science Insights, 2021 August 04; Vol. 38, No. 2, pp.305-313.

(c) 2021 Insights Publisher. All rights reserved.

Creative Commons Non Commercial CC BY-NC: This article is distributed under the terms of the Creative Commons Attribution-NonCommercial 4.0 License which permits non-commercial use, reproduction and distribution of the work without further permission provided the original work is attributed by the Insights Publisher.

$\mathrm{S}$ ELF-MANAGEMENT is a distinctive feature of human beings. Since Thoresen et al. proposed self-management (often called self-control) in the 1970s (1), self- management has been widely used in many fields. Studies have shown that improving learners' self-management ability can improve the treatment effect of chronic psychogenic and behavioral diseases in clinical treatment (2). In addition, it can enhance the learning effect of learners in the field of education ( 3 , 4). Through relevant staff training, personal performance can be improved (5).
Early self-management research objects were predominantly clinical treatment patients. In recent years, self- management research objects have expanded to student groups, the military, and human resources enterprises and institutions. Among them, middle school students are a particular group. Individual students in the middle school stage are in a period of self-unity formation; self-awareness is gradually formed, so they have a good foundation for acquiring and cultivating self-management. Therefore, the middle school stage is not only an important stage for students to receive knowledge but also a 
critical period for them to develop their consciousness.

Based on the research literature on self-management of middle school students in recent years, this paper describes the connotation and theoretical basis of self-management of middle school students from a multidisciplinary perspective, as well as the existing problems in practice and the shaping path and put forward the issues in current research and the direction of future research.

\section{Research Idea}

This article is based on literature analysis statistics and visualization tools, with the help of CiteSpace software to analyze "self-management" related content, examines keyword clustering, high-frequency citations, and discusses the status and trends of research on student self-management from 1992 to 2021. Take the data from CNKI databases, foreign open databases represented by Elsevier, and public materials in other related websites as the search objects, and search with "student self-management" as the subject term. As of June 4, 2021, a total of 5,387 results have been obtained. Furthermore, after screening irrelevant documents, set the research scope to "middle school" 256 related copies were obtained.

\section{Annual Publication Trend}

By analyzing the number of articles, we found that the research on self-management in China started in 1995 and showed a surge in 2009-2019. Therefore, it can be concluded that after the start of the first round of new curriculum reform, research on self-management has entered an upward trend in just a few years and reached a peak in 2019. This may be related to the Opinions on Deepening Education and Teaching Reform and Comprehensively Improving the Quality of Compulsory Education issued by the State Council in $2019^{\underline{I}}$. In this document, further requirements are made for teaching and management methods that guide students to explore and develop independently, reflecting the needs for students' self-management ability in the new era.

\section{Research Subject Analysis}

In research, elementary educators and secondary vocational teachers, mainly middle school teachers, occupy the leading group of researchers. This result may be closely related to the content and meaning of students' self-management. Due to the importance of basic education and secondary vocational education to student development and classroom teaching, the research and application of student self-management have become the research focus of educators at this level.

\section{Research Field Analysis}

In research, middle school, high school, and secondary vocational secondary education have become the main field of study. However, in addition to secondary education, higher education, elementary education, adult education, physical education, and other school education levels have paid great attention to this theme.

At the same time, we have also seen that in addition to education, other fields have paid attention to student self-management, such as psychology, medicine, language, economics, and public security. This also shows that self/autonomous management plays a vital role in guiding students in various fields and stages.

\section{Analysis of the Research Hotspots of Student Self-Management}

From the perspective of related research hot words, the hotspot analysis on student self-management focuses on the connotation of self-management, theoretical support, and the practice and evaluation of student self-management. Therefore, this paper then divides it into three aspects: academic research, practical research, and related evaluation research, to comprehensively summarize the research hotspots of student self-management.

\section{Related Theoretical Research}

\section{Research on the Connotation of Students' Self-Management}

Research on this issue has always been an essential topic of discussion in academia. In the early 20th Century, Mr. Xingzhi Tao proposed "student autonomy" and explained the definition of "student autonomy" in three layers. First, students refer to the classmates of the whole school, which means group. Second, autonomy means self-management, with the meaning of legislation, law enforcement, and justice. Third, student autonomy is slightly different from other autonomy because students are still there. Finally, in the school-age, there is a meaning of practicing autonomy (6). In terms of meaning, the "student autonomy" advocated by Xingzhi Tao is the autonomous management of students today.

With the advancement of the new curriculum reform, student self-management has received more extensive attention. As a result, scholars began to enrich and supplement the connotation of "student self-management" from different fields and perspectives. Like Wang and Jin explained the definition of self-management from the standpoint of psychology (7). They summed up the self-management of students as "individuals take the initiative to adjust their mental activities and behaviors, control improper impulses, overcome unfavorable situations, actively seek development, and obtain psychological qualities of good adaptation." Sun believed that "the self-management of middle school students is their management, the mental state, and behavior that dominated themselves and the external environment through their awareness and behavior" (8).

Some scholars have studied the content of students' self-management according to the different management roles. For example, Liu (2010) believes that self-management can be divided into individual self-management and collective self-management (9). The individual's self-management includes two parts: inside the school and outside the school. The internal part of the school consists of: self-management goal setting and realization.

Wei considered it to be "self-directed, self-motivating, and self-monitoring" management from the characteristics of self-management (10). Tan believed that students' self-management ability should include three aspects: learning autonomy, daily self-ability, and extracurricular practice ability (11). Xu and Qi summarized self-management into six elements: self-goal management, self-control management, self-creation 
management, self-regulation management, self-time management, and self-money management" (12). Finally, Wang divided the self-management content into self-management of psychological behavior, self-management of the classroom, and self-management of life (13).

Based on this, this article defines student self-management as student-centered, under positive guidance, giving full play to the subjective initiative of middle school students, and effectively integrating and utilizing various internal and external elements of learning and life. And through management methods such as planning, coordination, control, supervision, and scientific management methods, students are allowed to move from heteronomy to self-discipline and passively accept management to actively participate in management. Through self-learning, self-planning, and self-management, students can develop an educational management method for independent people with self-awareness, democratic awareness, and social awareness.

\section{Research on the Theoretical Support of Stu- dent Self-Management}

While studying the connotation of student self-management, its theoretical support has also become the focus of researchers. Student self-management is essentially a management concept, a management activity based on management goals and management plans. Therefore, management theory has a significant theoretical reference value for students' self-management. In addition, student self-management is also related to many fields such as psychology and pedagogy. Therefore, this article summarizes and summarizes the theoretical support of student self-management.

\section{Management Theory Represented by Drucker's Self-Management Theory}

Strictly speaking, Peter F. Drucker is the first scholar who put forward the concept of "self-management." In 1954, in the book The Practice of Management, an epoch-making concept-management by objectives was proposed. Since then, management has been created as a discipline and has been continuously developed in practice and theory. In 1999, Management Challenges for the 21st Century was published and published. The book pointed out that the key to self-management lies in understanding these key issues:" Who am I? What is my strength? How to work to achieve results? What are my values? Where do I belong? I don't belong there?" By understanding your strength, values, and areas you are best at, you can successfully carry out self-management and finally realize self-management.

Therefore, Cai and Shen believed that Drucker's management theory supports economic development and social transformation and lays a solid theoretical foundation for students' self-management (14).

\section{Psychological Theory Represented by Bandura's So- cial Learning Theory}

Wang and Jin believed that "A lot of research on self in the non-psychoanalytic sense does not directly discuss self- management issues, but most of them have different degrees of connection with self-management" (7). Various theoretical schools of psychology, such as behaviorism, humanism, and cognitive school, affect the development of self-management. Among them, Bandura's social learning theory is an essential theoretical basis for exploring self-management (15).

Based on the social learning theory of a ternary interaction system in which cognition, behavior, and environment continuously interact, individuals can actively adjust their influence on the external environment to change the external environment. At the same time, individuals can exert influence on themselves. For example, the goal adjustment process in self-regulatory learning proposes to refine the self-monitoring in the goal adjustment process into three steps of self-observation, self-evaluation, and self-reaction. This makes the adjustment target a learnable skill to perform self-management by learning monitoring skills (16).

\section{Educational Theory Represented by Suhomlynsky's Self-Education Thought}

In a broad sense, education is a social activity whose direct purpose is to influence people's physical and mental development, which is the same as the ultimate goal of self-management (17). Therefore, the tradition of integrating self-management thought in the field of pedagogy has a long history. Related research can be traced back to the "self-cultivation and righteousness" advocated in Chinese Confucian teaching ${ }^{2}$, including "know yourself" by Socrates in ancient Greece $e^{\underline{3}}$, and later "I think, therefore here I am" proposed by Descartes ${ }^{4}$ and "Children" proposed by Dewey. Centralism", self-education proposed by Sukhomlynsky, etc. Based on the field of education, scholars expounded self-management in education from different angles. Among them, the most influential one is Sukhomlynsky's self-education.

Given the characteristics of students' development and the lack of attention to human personality in pedagogy, Sukhomlynsky proposed that students conduct self-education in their spiritual lives. He emphasized that education should start from childhood and early adolescence to guide students to develop good labor discipline, work and rest system, and physical exercise habits, and in the process, through experience, overcome their weaknesses to recognize themselves and discover themselves critically. Only self-knowledge can be regarded as self-education, and through self-education, self-discipline can be cultivated; that is, a fully developed personality can be acquired (18).

\section{Related Practical Research}

In addition to theoretical research, the practice of student self-management has always been a topic of concern to educators and researchers. According to the keyword analysis, researchers primarily focus on cultivating students' self- management ability, class management, and subject teaching. Based on the connotation of students' self-management, this paper divides the existing related research into two levels: the problem research of students' self-management and the strategic analysis of students' self-management.

\section{Study on the Problem of Student Self-Management}

Zhang mentioned that the middle school education system at the emerging stage could easily overlook the cultivation of the 
self-management ability of middle school students, resulting in the lack of good self-control of most students (19). Yang conducted a questionnaire survey of 1,512 students in a middle school in his city and found that the current middle school students have poor self-care and self-discipline abilities, are unable to learn and participate in school management actively, and their self-management ability is seriously insufficient (20). Based on this, this article summarizes the current problems of middle school students' self-management into the following four aspects:

\section{Lack of Self-Management Ability in Life}

In the 1950s, with the rapid development of Japanese society and economy, Japanese adolescents generally suffered from new health problems (such as obesity tendency) due to lack of natural interest in life and high mental stress caused by reduced living ability and severe lack of exercise. The number of people with decreased eyesight has increased dramatically). They are socially inadequate, making friends, and the quality of making friends tends to decline. Ethical and moral concepts are weakened; the establishment of self-reliance tends to be slow and various problems (21).

After China enters the 21st Century, the health and education of young people are also facing the same problems as Japan in the last Century. Among them, the most notable performance is the lack of self-management ability in life. For example, in a survey of middle school students in five middle schools in a particular city by Huang et al., only $51.4 \%$ of middle school students were able to clean regularly (22); the awareness rate of adolescent development knowledge and AIDS prevention knowledge was only 27.3; The interpersonal relationship of friends and family members is only $68.7 \%$; only $40.8 \%$ of those who encounter setbacks without psychological pressure will not affect their diet and sleep; it can be concluded that the life skills of middle school students in this city are weak. Wang and Sun's survey also concluded that the status quo of the self-care ability of middle school students is not optimistic, especially in terms of life skills (23).

\section{Poor Learning Self-Management Ability}

Zeng and Liu compiled a "Self-education Questionnaire for Middle School Students" based on the four dimensions of students' self-knowledge-the generation of self-education motivation, self-demand - self-planning, self-practice (self-supervision - self-control) and self-feedback" (24). They also used this questionnaire to survey the 7 th to 12 th graders of a city's middle school. The results showed that the level of self-demand of middle school students was low; especially the self-supervision and self-control are poor. Among them, 8th-grade students have the lowest self-education level.

Coincidentally, Liu et al. used the "Learning Autonomy Scale" - compiled by Professor Weiguo Pang to conduct a questionnaire survey on the self-learning ability of middle school students in their school (25). It is found that middle school students have low self-regulation ability in the learning process. There are deficiencies in the reflection, summary, and improvement of learning results, and further guidance is needed.

\section{Flawed Self-Management Initiative of the Class}

Chen believed that despite the experience in class management, the atmosphere of "little society" in the class is getting heavier, leading to the weakening of the function of student collective organization and the weakening of students' joint concept and democratic consciousness (26). Wang found that the sense of self-management of the class was not strong in his survey area (13). To a large extent, he still relied on the head teacher's authoritative and authoritarian management method.

Although middle school students have a sense of self-management, only $38 \%$ of students are willing to take the initiative to manage class discipline matters. This reflects the severe lack of students' initiative to participate in class management. Zhang and Yang came to the same conclusion after investigating the 9th-grade students of the school (27). It is believed that although the self-management ability of some students has been dramatically improved, there are still students who have begun to develop self-awareness and self-centered problems. In addition, some students emphasize other disciplines and neglect self-discipline.

\section{Poor Self-Management Ability in Social Practice Activ- ities}

Ding conducted a survey of 566 students, teachers, and parents in 8 different types of schools (urban public, county public, and private) schools (28). It is found that most students have a deviation in the concept and understanding of social practice in middle schools, and their autonomy and purpose are insufficient. Nearly $30 \%$ of students think that participating in social practice is just to have time for free activities and relieve the pressure of learning; almost $20 \%$ of students are right Participating in social practice takes an indifferent attitude. Wang also mentioned that middle school students lack self-management awareness, unclear self-management goals, and passive self-management when participating in social practice activities (29).

Deng compared the social practice activities of middle school students in China and other countries and concluded that Chinese middle school students are not very active in developing social practice activities (30). He believed that compared with the practice activities carried out by students as the main body in foreign countries; the voluntary nature of Chinese students to participate in social practice activities had been ignored. Correspondingly, their initiative and enthusiasm were also decreasing. The expectations of social practice were often not ideal. Social practice activities became coping activities, and their role was ignored.

\section{Research on Students' Self-Management Strategy}

Guided by student self-management, the school continues to innovate and develop, combining teaching management with the development of student self-management, forming a self-management strategy suitable for the development of school students. Therefore, students' self-management strategies are also one of the crucial themes that researchers pay attention to.

Based on the sorting and research of related literature, this article will sort out the strategies to improve students' self-management ability. It mainly includes the following aspects: 


\section{Build Awareness of Self-Management}

The humanistic philosopher Maslow's hierarchy of needs theory believes that everyone will have a desire to be respected and realize self-worth in their hearts in the process of self-fulfilling tasks (31). Students want to be recognized in the hope that they can perform better in various ways. This requires a certain amount of effort, and this effort will be transformed into self-management and control. Therefore, Zhang believes that self-management literacy requires conscious training and nurturing of external forces (32). For example, families and schools should implant the concept of "self-management" into students" hearts from childhood. Awaken the sense of self-management, start with helping students build self-management through the guidance and schooling.

Wen started with self-learning and believed that teachers must first establish a teaching philosophy that encourages students to learn independently, actively guiding students to understand the importance of self-learning ability correctly and understanding the internal connection between learning ability and future development (33). Thus, stimulates students' learning motivation, strengthens their self-learning awareness, establishes correct personal development goals, corrects learning attitude, establishes learning motivation, and devotes themselves to learning activities.

Family and school are the two prominent educational supporters in the growth of students. Liang believed that home-school cooperation was a meaningful way to help students build self-management awareness and behavior (34). Schools and families work together in self-learning, self-planning, self-time management, and self-health management, forming a solid educational force.

\section{Optimize Classroom Learning Methods}

Student self-management emphasizes student spontaneity and autonomy. In learning, autonomous learning spontaneously is the critical performance of students' self-management. It is also the realistic basis and prerequisite guarantee for students to develop and cultivate themselves in learning. Only with a certain degree of autonomy can students learn independently and then have the ability to grow alone (35). Therefore, optimizing classroom learning methods and enhancing students' learning initiatives are important ways to improve students' self-management ability.

Sun (2018) took the specific practice of the school as an example and put forward the primary purpose of student development, highlighted the subjectivity of students as the core, and developed conscious and active learning and behavior habits as the key (15). Let students become the "three-step guided learning" autonomous classroom model for educating themselves. In this model, teachers can instruct, guide, and help students achieve efficient learning through independent learning, group discussions, exchanges, and presentations.

Zhang took students from secondary vocational schools as an example and proposed that educators abide by the school's teaching system and implement typical teaching plans (36). At the same time, some courses are set up in the teaching to help cultivate students' sense of self-management to realize the change from simple passive acceptance to active seeking self-management.

\section{Establish and Improve Student Self-Management System}

A well-regulated management system can help students better restrain their behavior and improve their self-management ability. On the contrary, if the rules and regulations are not mature enough, it will be difficult for students to adjust to the benchmark. As a result, the self-management ability will be significantly reduced. Therefore, the construction of the self-management system focuses on enabling students to recognize and educate themselves.

Ji believed that to standardize system construction, different management models can be adopted (37). Furthermore, by letting students feel the influence of social rules and regulations on their behavior, they will take self-management seriously in the management process. Meanwhile, various reward and punishment mechanisms should be adopted to increase students' emphasis on self-management.

Sun also mentioned the establishment of a management system in his research (15). In its school management practice, it is based on system management. Under the premise of trusting and respecting students, it creates an educational environment in which everyone actively participates, manages independently, and is culturally nurtured to realize students' self-education, self-management, and self-development.

\section{Strengthen Student Social Practice Activities}

Practical activities are of great value to the cultivation of students' self-management ability. It can allow students to grasp the specific measures of self-management ability.

Ji believed that through some practical activities inside and outside the school, such as beautifying the campus environment inside the school and taking turns on duty, students can realize the vital value of self-management ability (37). Then through off-campus practical activities to help students clearly understand self-management, rationally position their development, and formulate feasible action goals.

Zhang also believed that educators should actively guide students to participate in teaching practice activities (36). For example, create a series of campus activities that students independently join in and design, or seize the opportunity to develop a platform to organize some unusual class activities. In addition, students can gain self-management ability in the whole process of participating in the activities.

\section{Rely on Information Technology, and Innovate the Training Strategies}

In the existing literature, the integration of information technology with teaching or management is the primary education trend. Especially after the outbreak of the COVID-19 pandemic, schools pay more attention to using the Internet to guide students to carry out independent learning and independent management $(38,39)$. Although the research on students' self-management strategy with educational informationization is rare, the researchers stated that the student's self-management strategy supported by informationization plays an important role. 
For example, Qian believes that middle school students must have self-management to effectively mobilize their initiative, plan and control their actions, and adapt to the community and individual growth in the face of a diverse and open information society (40).

\section{Conclusion and Perspective}

As a research subject, self-management has become a frontier and hot topic in many disciplines. Around this theme, research disciplines such as psychology, management, education, and medicine have been formed. Each discipline uses the professional perspective and research methods of the field to define its connotation and definition, construct the structure and find effective measurement methods, explore the dependent and independent variables that affect self-management and find the system to cultivate and form self-management capabilities and path.

After the new curriculum reform, China has also paid attention to the study of student self-management in the field of education and formed a relatively prosperous and systematic theory and implementation strategy. However, due to the small number of empirical studies related to student self-management at this stage, the quality and quantity of research are unstable. Therefore, this article only conducts relevant research and analysis on higher frequency download documents. Nevertheless, through the study of the development and content of self-management of domestic middle school students, the discussion of the problems and strategies of student self-management, and the summary of practical effects, the following conclusions are drawn:

First, the number of articles is considerable. Second, from the perspective of the time distribution of research, scholars have gradually increased their research on student self-management in recent years. As a result, the study of student self-management has become one of the hot topics. Third, even though there is a downward trend at this stage, it is foreseeable that with the gradual improvement of the COVID-19 pandemic, the changes in teaching and learning methods brought about by the epidemic will put higher demands on students' self-management ability. Therefore, in the next few years, the research literature on student self-management will show an increasing trend.

Second, the research perspective is diversified. Scholars' research on student self-management is limited to education and social aspects and considers student self-management from the multidisciplinary standpoint of psychology, sociology, anthropology, and medicine. This provides a multi-path reference for the effective implementation of students' self-management.

Third, the research topics are rich. Judging from the existing research, the research on student self-management covers all stages of preschool education, basic education, higher education, vocational education, and special education. Moreover, the study includes the theoretical aspects, such as its related meaning and value, and the practical aspects, such as the implementation effect of students' self-management.

However, the research on the self-management of middle school students has the following shortcomings as a whole. The discussion of these shortcomings is to provide the direction for our future research.

First, the research content pays more attention to the management content of the head teacher and neglects other aspects of the student's individual development. Second, even though autonomous learning is considered one of the critical contents of self-management, it is not presented much in the literature on student self-management. This makes the content of student self-management inconsistent with actual research and lacks systematic research on student self-management.

Second, in terms of research objects, the students of higher vocational colleges, mainly universities, are the groups that researchers pay more attention to. But from the perspective of individual development, self-management at the middle school stage can lay a solid foundation for student's future learning and development. Unfortunately, self-management for middle school students, especially their self-management, has not become the focus, and the amount of relevant research literature is relatively small. This has led to the use of the whole-stage research literature in some research questions, trying to summarize the characteristics of middle school students' self-management from the literature of other stages, and the research conclusions may need to be further confirmed.

Third, the research perspective is single, and there is a lack of interdisciplinary research. The complexity of self-management needs to rely on the theory and research perspective of the subject. The self-management research of existing middle school students is not synchronized with the self-management research. Many educators have only summarized and described their experiences based on their personal experiences. They have not drawn on the more mature research results and conclusions in the self-management field. The level of research on self-management of middle school students needs to be deepened.

Fourth, the research method is single, and diversified research methods need to be introduced. Diversity and improvement of research methods are essential guarantees for in-depth research. For example, the current research on self-management of middle school students is based on experience and few empirical studies. Given the complexity of self-management, future research should adhere to quantitative and qualitative research, focusing not only on breakthroughs in theoretical research but also on applied research.

Fifth, the systematic research based on the improvement of individual self-management ability is fragile. Most of the existing research conclusions and recommendations lack practicality or effectiveness. There is a disconnection between theoretical research and practical research, especially for the feasibility of intervention and improvement of self-management level. In the future, the structure and influencing factors of self-management need to be clarified more. System and operation intervention programs and strategies should be developed to improve the self-management ability of middle school students. 
1. The Opinions of the Central Committee of the Communist Party of China and the State Council on Deepening Education and Teaching Reform and Comprehensively Improving the Quality of Compulsory Education is a document issued by the Central Committee and the State Council on June 23, 2019. The document focuses on deepening education and teaching reforms and comprehensively improving the quality of compulsory education. It is a programmatic document that has issued a series of measures.

2. The eighth chapter of "Da Xue" talked about "the so-called self-cultivation is to correct the heart. If the body is irritated, it cannot be corrected. If there is fear, it cannot be corrected. If there is happiness, it cannot be corrected. Suffering cannot be corrected. Absent-mindedness, blindness, hearing and not smelling, eating but not knowing its taste. This means that self-cultivation is righting one's heart." It aims to explain that to cultivate one's character; one must first correct one's mind and put forward the path of self-management and self-cultivation.

3. It was initially engraved on the lintel of the ancient Greek temple of Delphi with such an oracle- "Human! Know yourself." Later it was cited by Socrates as his philosophical purpose, advocating reflecting on oneself from the starting point of "knowing oneself" to discover the truth of things.

4. It is the starting point of Descartes' epistemological philosophy and the end of his "general suspicion, "emphasizing self-subjective consciousness.

5. The "Learning Autonomy Scale" was compiled by Professor Weiguo Pang in 2013. This is a set of self-reporting horoscopes suitable for junior high school students' autonomous learning ability, which can objectively, uniformly, and efficiently complete the testing of junior high school students' autonomous learning ability. The scale has a total of 113 questions, which analyze the current situation of middle school students' independent learning ability from the seven dimensions of learning motivation, learning content, learning time, learning methods, learning process, understanding results, and learning environment. Five points are used: "Never do this," score 1 point, rarely do this," score 2 points, "sometimes this" score 3 points, "always make this" score 4 points, and "always do this" score 5 points.

\section{References}

1. Thoresen CE, Mahoney MJ. Behavioral self-control, New York: Holt, Rinehart \& Winston. 1974.

2. Lorig KR, Holman, HR. Self-management education: History, definition, outcomes, and mechanisms. Ann Behav Med 2003; 26(1):1-7. DOI: http://dx.doi.org/10.1207/S15324796ABM2601 01

3. Schunk DH, Zimmerman BJ. Social origins of self-regulatory competence. Educ Psychol 1997; 32(4):195-208. DOI: https://doi.org/10.1207/s15326985ep3204 1

4. Long JD, Gaynor P, Erwin A. Williams R L. The relationship of self-management to academic motivation, study efficiency, academic satisfaction, and grade point average among prospective education majors. Psychology 1994; 31(1):22-30. https://psycnet.apa.org/record/1994-39231-001

5. Manz CC, Keating DE, Donnellon A. Preparing for an organizational change to employee self-management: The managerial transition. Organiz Dynam 1990; 19(2):15-26. DOI: https://doi.org/10.1016/0090-2616(90)90068-Z

6. Tao XZ. Research on Student Autonomy. Teach Manag Educ Res 2018; 3(7):4-8. [Chinese] https://doi.org/10.3969/j.issn.2096-224X.2018.07.003

7. Wang YM, Jin Y. A review of self-management research. J Psychol Sci 2002; 21(4):453-456+464.

\section{[Chinese] \\ https://doi.org/10.16719/j.cnki.1671-6981.2002.04.01} $\underline{9}$

8. Sun W. On the self-management of students in the new curriculum reform. Res Finan Educ 2006; 4(6):160-161. [Chinese] http://www.cnki.com.cn/Article/CJFDTotal-JXJR2006 06060.htm

9. Liu XY. Research the problems and countermeasures in junior high school students (Master's Dissertation) Liaoning Normal University. 2010. DOI: [Chinese] https://doi.org/10.7666/d.Y1801658

10. Wei $Y$. Independent management promotes the independent and healthy growth of students. Chin Metallurg Educ 2004; 11(5):80-82. [Chinese] https://doi.org/10.16312/j.cnki.cn11-3775/g4.2004.05. $\underline{024}$

11. Tan JG. The content and methods of self-management ability training for middle school students. Educator 2018; 20(16):79. [Chinese] http://www.cnki.com.cn/Article/CJFDTotal-JYYR2018 16067.htm

12. Xu DY, Qi LL. Talking about the self-management of middle school students. Sci Educ Articl Cult 2008; 2(24):49-50. [Chinese] https://doi.org/10.3969/i.issn.1672-7894.2008.24.042

13. Wang J. Research on self-management of middle 
school students (Master's thesis, Guangzhou University). 2017. Available at:

https://kns.cnki.net/KCMS/detail/detail.aspx?dbname $=$ CMFD201901\&filename $=1018247682$.nh

14. Cai $Y H$, Shen XY. Literature review of student self-management research. //Proceedings of the $\mathrm{Na}$ tional Education Management Symposium and the Sixth Executive Director Enlarged Conference of the Education Management Branch of the Chinese Education Society. 2012; pp80-pp90. [Chinese] https://d.wanfangdata.com.cn/Conference/7935488

15. Sun XM, Xue G. Self-management research review and prospects. Adv Psychol Sci 2008; 26(1):106-113. [Chinese]

http://www.cnki.com.cn/Article/CJFDTotal-XLXD2008 01018.htm

16. Bandura A. Social Learning Theory. New York: General Learning Press. 1977.

17. Guo HL, Tan HL. Discussion on the interaction between self-management and education. Theor Reform, 2005; 20(4):140-142. [Chinese] http://www.cnki.com.cn/Article/CJFDTotal-LLGG2005 04043.htm

18. Sukhomlynsky V. Educational Trilogy (S. Bi, Trans). People's Education Press. 1998. [Chinese]

19. Zhang CP. Discussion on the self-management of junior high school students under the background of the new curriculum reform. New Wisdom 2019; 2(35):23. [Chinese]

http://qikan.cqvip.com/Qikan/Article/Detail ?id=00002 EOCL9707JP167D04JP0MJR

20. Yang J. Problems and countermeasures of self-management of junior high school students. New Curricul 2014; 7(6):148-149. [Chinese]

https://doi.org/10.3969/i.issn.1673-2162.2014.06.392

21. Liu YZ, Zhang DW. Cultivating students' living abilities: A new perspective on Japan's basic education reform. Moder Element Mid Sch Educ 1997; 13(5):9-11. [Chinese]

http://www.cnki.com.cn/Article/CJFDTotal-XDZX1997 05003.htm

22. Huang $Y$, Chen XF, Wang CS. Investigation on the status quo of middle school students' self-care ability. Psychologist (second half of the month) 2012; 1(10):11-12. [Chinese] http://med.wanfangdata.com.cn/Paper/Detail/Periodi calPaper xlys-xbyb201210013

23. Wang ZX, Sun ZQ. Investigation on the status quo of self-care ability of middle school students in modern life. Med Aesthet Cosmetol (Mid-day issue), 2014; 3(3):303-303. [Chinese]

http://med.wanfangdata.com.cn/Paper/Detail/Periodi calPaper yxmxmr-zx201403356

24. Zeng XF, Liu HX. Investigation on the status quo of middle school students' self-education. J Xuzhou Norm Univ (Education Sciences) 2012; 3(04):52-55. [Chinese] http://www.cnki.com.cn/Article/CJFDTotal-XZSJ2012 04019.htm

25. Liu YF, Zhang HY, Liu QJ, Zhang Y, Wang JJ. Analysis of the status quo and cultivation of autonomous learning ability of junior high school students. Educ
Modern 2019; 6(89):213-217. [Chinese] https://doi.org/10.16541/i.cnki.2095-8420.2019. $\underline{89.090}$

26. Chen GS. Talking about "Self-management of Student Organizations." Henan Educ 2001; 8(7):43. [Chinese]

http://www.cnki.com.cn/Article/CJFDTotal-TECH2001 07047.htm

27. Zhang CY, Yang JG. Investigation and analysis of the status quo of class self-management of junior high school students. Modern Educ (Electronic Edition) 2017; 17:260-260. [Chinese]

http://www.cqvip.com/QK/72031x/201717/epub10000 00968994.html

28. Ding MM. Research on establishing social practice mechanisms in middle schools. (Master's Dissertaton) Northeast Normal University. 2009. [Chinese] http://cdmd.cnki.com.cn/Article/CDMD-10200-20091 77995.htm

29. Wang Y. Problems and countermeasures of self-management by middle school students (Master's Dissertation). Inner Mongolia Normal University. 2013. [Chinese]

http://cdmd.cnki.com.cn/Article/CDMD-10135-10132 69491.htm

30. Deng HF. A comparative study of Chinese and foreign social practice activities of middle school students. (Master's Dissertation). Henan University 2013. [Chinese] DOI: https://doi.org/10.7666/d.D371241

31. Maslow AH. Motivation and personality. New York: Harper \& Row. 1970.

32. Zhang CW. The meaning, structure, and cultivation of students' self-management literacy. Teach Manag 2021; 38(3):15-17. [Chinese]

https://d.wanfangdata.com.cn/periodical/jxygl-||lb2021 $\underline{01005}$

33. Wen YF. Strategies to improve students' self-learning ability. Theor Pract Educ 2020; 40(11):51-53. [Chinese]

http://www.cnki.com.cn/Article/CJFDTotal-JYLL20201 1015.htm

34. Liang YM. Home-school cooperation on the cultivation of junior high school students' self-management ability. Teacher 2021; 15(7):13-14. [Chinese] http://qikan.cqvip.com/Qikan/Article/Detail?id=71042 $\underline{71029}$

35. Liu C. An analysis of students' autonomous learning. Educ Res 2014; 35(7):131-135+159. [Chinese] http://www.cnki.com.cn/Article/CJFDTotal-JYYJ2014 07019.htm

36. Zhang J. On the cultivation and significance of the self-management ability of music majors in teaching. Music Time Spac 2016; 6(6):137+136. [Chinese] http://www.cnki.com.cn/Article/CJFDTotal-YYSK2016 06078.htm

37. Ji F. Strategies for cultivating students' self-management ability. Teach Ref Mid Sch Politic 2018; 25(3):54-55. [Chinese] http://www.cnki.com.cn/Article/CJFDTotal-ZXZZ2018 03024.htm

38. Chen WL. Self-management and autonomous learn- 
ing, the critical literacy of online education. Educator 2020; 6(13):64-65. [Chinese]

http://www.cnki.com.cn/Article/CJFDTotal-JYJA2020 13026.htm

39. Yang W. Difficulties and breakthroughs in student management in primary education in the post-epidemic era. Foreig Languag 2020; 19(36):73-74+107. [Chinese]

https://kns.cnki.net/kcms/detail/detail.aspx?dbcode= $\underline{\text { CJFD\&dbname }=\text { CJFDLASN2021\&filename }=K W Y W}$ $202036037 \& v=U j 7 Z L X g P B r O X Y 1 \% 25 m m d 2 F B I h w S p$ fKfDmeKUugwzledotGByDz6KVT6NQ8TyRTkQ\%25 mmd2Ft5Im99

40. Qian XL. The cultivation of students' self-management ability in the information society. Chin Educ Innov Herald 2010; 17(21):219. [Chinese] https://doi.org/10.3969/j.issn.1673-9795.2010.21.206 